\section{Literature Cited}

1) Bajpai, R. K. and M. Reuss: Can. J. Chem. Eng., 60, 384 (1982).

2) Elliott, J. H.: "Extracellular Microbial Polysaccharides" (ACS Symposium Series No. 45, P. A. Sanford and A. Laskin, eds.), p. 144, American Chemical Society, Washington, D. C. (1977).

3) Funahashi, H., M. Maehara, H. Taguchi and T. Yoshida: $J$. Chem. Eng. Japan, 20, 16 (1987).

4) Inoue, I. and K. Sato: Kagaku Kōgaku, 33, 293 (1969).
5) Metzner, A. B. and J. S. Taylor: AIChE J., 6, 109 (1969).

6) Mukataka, S., H. Kataoka and J. Takahashi: Kagaku Kogaku Ronbunshu, 2, 628 (1976).

7) Mukataka, S., H. Kataoka and J. Takahashi: Kagaku Kogaku Ronbunshu, 3, 416 (1977).

8) Mukataka, S., H. Kataoka and J. Takahashi: Kagaku Kogaku Ronbunshu, 4, 34 (1978).

9) Sato, K. and I. Inoue: Kagaku Kögaku, 37, 937 (1973)

10) Yuge, K. and E. Oshima: Kagaku Kōgaku, 33, 898 (1969)

11) Yuge, K. and E. Oshima: Kagaku Kögaku; 34, 439 (1970).

\title{
EMULSION PHASE EXPANSION AND SEDIMENTATION VELOCITY IN FLUIDIZED BEDS OF FINE PARTICLES
}

\author{
TAKAMI KAI, AKIKO IWAKIRI AND TAKESHIGE TAKAHASHI \\ Department of Chemical Engineering, Kagoshima University, Kagoshima 890
}

Key Words: Fluidization, Fluidized Bed, Bed Expansion, Minimum Fluidization Velocity, Sedimentation

\begin{abstract}
In fluidized beds of fine particles, minimum fluidization velocity $U_{m f}$, voidage of the emulsion phase $\varepsilon_{e}$ and sedimentation velocity $U_{s}$ were measured for various gas-powder systems. For both $U_{m f}$ and $U_{s}$, the relationship between velocity and voidage was experimentally determined on the basis of the Richardson-Zaki equation. The voidage of the emulsion phase was correlated by a dimensionless parameter taking into account the effect of gas density. By using this correlation and the relationship between velocity and voidage obtained in this study, $U_{s}$ was expressed as a function of $U_{m f}$. The calculated $U_{s}$ from $U_{m f}$ agreed with the experimental data.
\end{abstract}

\section{Introduction}

Many industrial fluidized catalytic reactors use fine powder catalysts less than $100 \mu \mathrm{m}$ in diameter, since good fluidization and good gas-solid contact can be easily established in this size range. Beds of fine, lowdensity particles homogeneously expand between minimum fluidization and minimum bubbling points. When the beds are fully fluidized, voidage of the emulsion phase is also higher than that of settled beds or that at minimum fluidization. The extent of expansion of the emulsion phase is an important factor ${ }^{6)}$ in the prediction of the bed's performance as a chemical reactor and in the estimation of the apparent viscosity of the emulsion phase, which relates to bubble size and fluidization quality.

The purpose of this study is to investigate the expansion behavior of the emulsion phase and to reveal the influence of the properties of gas and particles on the expansion. We measured minimum fluidization velocity $U_{m f}$, sedimentation velocity $U_{s}$ and the voidage of the emulsion phase $\varepsilon_{e}$ for various

Received September 26, 1986. Correspondence concerning this article should be addressed to T. Kai. gas-powder systems.

\section{Experimental}

The physical properties of the particles used in this study are given in Table 1. All powders are within Group A of the Geldart ${ }^{3}$ classification when air is used as the fluidizing medium. The particles were moistened in the pores to decrease the influence of electrostatic charges. ${ }^{7,10)}$

The experiments were carried out in an acrylic resin column $5.5 \mathrm{~cm}$ in diameter and $2.2 \mathrm{~m}$ in height under ambient conditions. The settled bed height above a gas distributor was $0.6 \mathrm{~m}$. The distributor was made of sintered brass and was $3 \mathrm{~mm}$ thick. Eight gases were used as the fluidizing gas: argon, oxygen, helium, nitrogen, carbon dioxide, ethylene, methane and hydrogen.

The minimum fluidization velocity was determined from the usual plot of pressure drop against superficial gas velocity. The expansion behavior of the emulsion phase was investigated by using the bed collapse technique. ${ }^{12,15)}$ After the gas velocity had been set at about $0.1 \mathrm{~m} \mathrm{~s}^{-1}$ and the bed had been well fluidized, the gas supply was suddenly stopped $(t=0)$ 
Table 1. Properties of particles

\begin{tabular}{lrrrr}
\hline Particles & $\begin{array}{c}\bar{d}_{p} \\
{[\mu \mathrm{m}]}\end{array}$ & $\begin{array}{c}\rho_{p} \\
{\left[\mathrm{~kg} \cdot \mathrm{m}^{-3}\right]}\end{array}$ & $\begin{array}{c}F \\
{[\%]}\end{array}$ & $\begin{array}{c}* U_{m f} \\
{\left[\mathrm{~cm} \cdot \mathrm{s}^{-1}\right]}\end{array}$ \\
\hline $\begin{array}{l}\text { Alumina } \\
\text { Al-1 }\end{array}$ & 55.0 & 770 & 18 & 0.098 \\
Al-2 & 83.2 & 770 & 1 & 0.220 \\
Silica-alumina & & & & \\
FCC-1 & 35.8 & 920 & 60 & 0.061 \\
FCC-2 & 37.4 & 1050 & 51 & 0.068 \\
FCC-3 & 34.7 & 1750 & 60 & 0.105 \\
FCC-4 & 48.4 & 1690 & 26 & 0.195 \\
FCC-5 & 56.3 & 980 & 18 & 0.127 \\
Silica & & & & \\
Si-1 & 69.3 & 570 & 6 & 0.155 \\
Si-2 & 105.1 & 1300 & 3 & 0.508 \\
\hline * Fluidized by nitrogen & & & \\
\hline \multicolumn{5}{r}{} \\
\hline
\end{tabular}

and the change of bed height was recorded with time. The equivalent height, $L_{e}$, of the emulsion phase in the aggregative bed was determined by extrapolating the collapse curve to time zero. The sedimentation velocity, $U_{s}$, was obtained ${ }^{12,13)}$ from the collapse rate and the leaking gas velocity, which was measured at the column entrance.

\section{Results and Discussion}

\subsection{Relationship between velocity and voidage}

The minimum fluidization velocity for the bed of fine particles can be expressed by the following wellknown equation:

$$
U_{m f}=\frac{1}{K_{f}} \frac{\bar{d}_{p}^{2} g\left(\rho_{p}-\rho\right)}{\mu} \frac{\varepsilon_{m f}^{3}}{1-\varepsilon_{m f}}
$$

The value of $K_{f}$ is 150 according to the modified Ergun equation. ${ }^{9}$ In the present study, however, the average values of $K_{f}$ were found to be 248 for rounded particles and 282 for angular particles. The analysis of packed data by Abrahamsen and Geldart ${ }^{1)}$ gave an average of 263 for spherical and very rounded particles. Since $K_{f}$ was much larger than 150 even for the rounded particles, the disagreement might not be caused by the effect of the sphericity of particles alone. On the other hand, the difference of $K_{f}$ between rounded and angular particles was probably due to the difference in sphericity. A sphericity of 0.87 was obtained for $\mathrm{Si}-2$, which was the most angular of the particles, from the ratio of experimental $K_{f}$ by assuming that the sphericity was unity for the particles which had the smallest value of $K_{f}$.

The homogeneous expansion behavior has been described $^{1,16)}$ on the basis of an equation similar to Eq. (1). As $U_{s}$ is considered to be equal to the superficial velocity of the gas flowing through the bed of which the voidage is equal to that of the emulsion phase, $\varepsilon_{e}{ }^{12)}$ the relationship between $U_{s}$ and $\varepsilon_{e}$ can be expressed as:

$$
U_{s}=\frac{1}{K_{f}} \frac{\bar{d}_{p}^{2} g\left(\rho_{p}-\rho\right)}{\mu} \frac{\varepsilon_{e}^{3}}{1-\varepsilon_{e}}
$$

The average value of $K_{f}$ for $\varepsilon_{e}$ found in the present study by using Eq. (2) was 226 . The value of $K_{f}$ was smaller for $\varepsilon_{e}$ than for $\varepsilon_{m f}$.

The expansion behavior in homogeneous gas fluidized beds can also be described by the Richardson$\mathrm{Zaki}^{14)}$ equation:

$$
U_{f}=U_{t} \varepsilon^{n}
$$

for solid-liquid systems. When the flow regime was laminar, the value of $n$ was about 4.65 for liquid fluidized beds. ${ }^{14)}$ For gas fluidized beds, the values of $n$ found by Massimilla et al. ${ }^{10}$ for catalyst particles ranged from 5.41 to 7.12 depending on size. For the expansion of the emulsion phase, $U_{f}$ and $\varepsilon$ in Eq. (3) are replaced respectively with $U_{s}$ and $\varepsilon_{e}$. In laminar flow conditions the equation becomes

$$
U_{s}=\frac{\bar{d}_{p}^{2} g\left(\rho_{p}-\rho\right)}{18 \mu}-\varepsilon_{e}^{n}
$$

The value of $n$ of each powder system can be determined by varying gas viscosity. In Fig. 1, $U_{s} \mu$ is plotted as a function of $\varepsilon_{e}$ for $\mathrm{Al}-1$, and the value of 5.3 for $n$ is obtained. It is also seen that the relationship between $U_{s} \mu$ and $\varepsilon_{e}$ cannot be described by the function, $\varepsilon^{3} /(1-\varepsilon)$. Geldart and Wong ${ }^{4)}$ found that the value of $n$ becomes larger than 4.65 due to the interparticle forces in fluidized beds with fine particles. It is considered that for the same reason it is difficult to correlate $U_{s}$ with the function $\varepsilon^{3} /(1-\varepsilon)$. When this function is still used, the obtained values of $K_{f}$ differ from the theoretical values and vary with voidage.

The shape and roughness of particles are not taken into account in the mean particle size $\bar{d}_{p}$ in Eq. (4). In addition, it is uncertain whether $\bar{d}_{p}$ is suitable for particles having a broad size distribution. Nevertheless, we used $\bar{d}_{p}$ in the form of Eq. (4) for convenience. As shown in Fig. 2, when $n$ was set equal to 5.8 the calculated velocities agreed with the experimental data within $\pm 20 \%$ accuracy for $U_{s}$ and $U_{m f}$ of all gas-powder systems.

\subsection{Sedimentation velocity}

Figure 3 illustrates effects of gas viscosity on $U_{s}$. For Al-2, which was relatively large, and for FCC-4, which was relatively heavy, $U_{s}$ decreased with increasing gas viscosity. This tendency is directly predicted from Eq. (2). However, for FCC-1, which was the smallest, $U_{s}$ was almost independent of gas viscosity. For one powder system, the velocity $U_{s}$ is a function of gas viscosity and the voidage $\varepsilon_{e}$, i.e., $U_{s} \propto \varepsilon_{e}^{n} / \mu$. For large particles the voidage $\varepsilon_{e}$ is not much affected by gas viscosity and $U_{s}$ is almost inversely proportional 


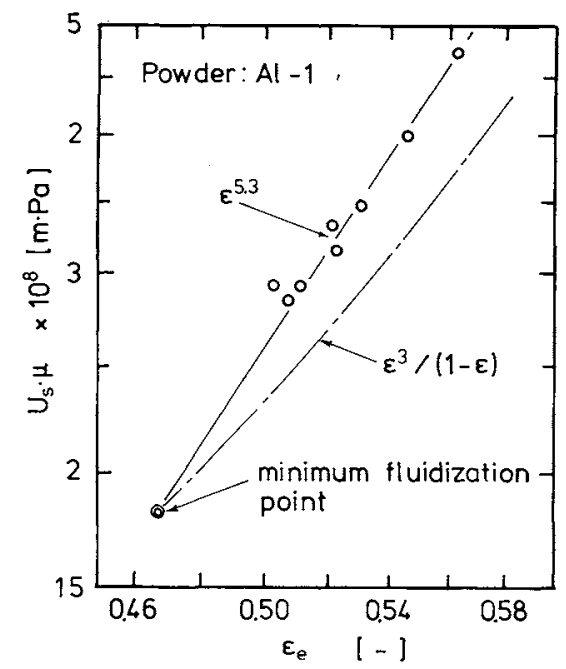

Fig. 1. Relationship between $\varepsilon_{e}$ and $U_{s} \mu$ for Al-1.

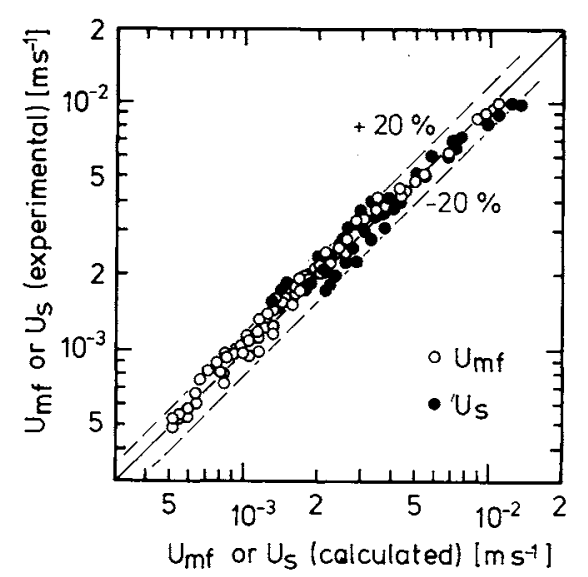

Fig. 2. Comparison of experimental values of $U_{m f}$ and $U_{s}$ with predicted by Eq. (3) at $n=5.8$.

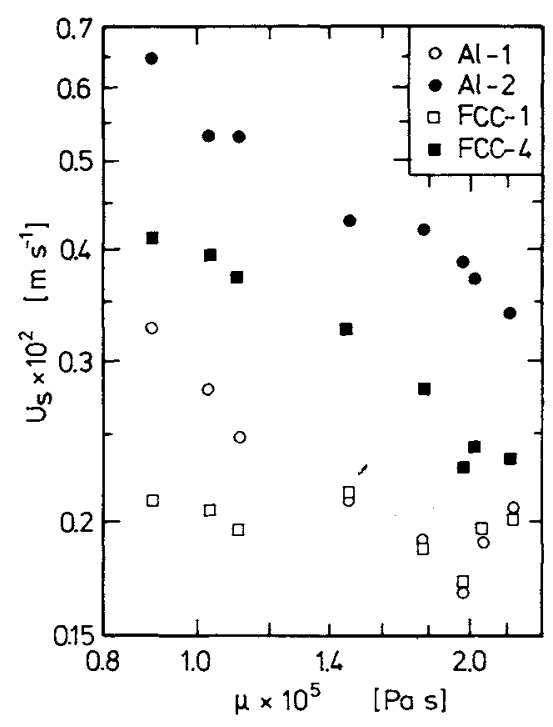

Fig. 3. Effect of gas viscosity on sedimentation velocity.

to the viscosity. However, for fine particles, since the voidage $\varepsilon_{e}$ increases with gas viscosity, $U_{s}$ is almost independent of gas viscosity. This tendency was also revealed by comparing $U_{s}$ with $U_{m f}$.

Figure 4 shows the relationship between $U_{m f}$ and $U_{s}$ for the data measured in the present study and by other investigators. ${ }^{5,12,13,17)}$ For the results of Weimer et al. ${ }^{17)}$ only the data at ambient pressure were used. When $U_{m f}$ was larger than $0.1 \mathrm{~cm} \mathrm{~s}^{-1}, U_{s}$ increased with $U_{m f}$. When $U_{m f}$ was smaller than $0.1 \mathrm{~cm} \mathrm{~s}^{-1}, U_{s}$ was almost constant or increased with decreasing $U_{m f}$.

\subsection{Voidage of the emulsion phase}

Abrahamsen and Geldart ${ }^{2)}$ have presented a correlation for predicting $\varepsilon_{e}$ :

$$
\frac{1-\varepsilon_{m f}}{1-\varepsilon_{e}}=\frac{2.54 \rho^{0.016} \mu^{0.066} \exp (0.090 F)}{\bar{d}_{p}^{0.1} g^{0.118}\left(\rho_{p}-\rho\right)^{0.118} L_{m f}^{0.043}}
$$

The experimental values of $\varepsilon_{e}$ are compared with the predictions from Eq. (5) in Fig. 5. Although the deviations in the predicted values were relatively small, the predictions were not directly proportional to our experimental results. When gas viscosity and density became low and $\varepsilon_{e}$ was small, the predictions from Eq. (5) were underestimated and became even smaller than $\varepsilon_{m f}$ for some data.

Morooka et al. ${ }^{12)}$ have correlated the expansion ratio of the emulsion phase, $\alpha=\left(L_{e}-L_{q}\right) / L_{q}$, with the dimensionless number

$$
N=\sqrt{g \bar{d}_{p}^{3}}\left(\rho_{p}-\rho\right) / \mu
$$

Figure 6 shows the relationship between $\alpha$ and $N$. The expansion ratio $\alpha$ was inversely proportional to $N$ for each powder. The points near the lower line (narrow FCC) were the results obtained by hydrogen and helium. The expansion ratio for these gases was smaller than that predicted from the value of $N$, since the expansion behavior of the emulsion phase was influenced not only by gas viscosity but also by gas density. ${ }^{2,8)}$

To correlate the voidage $\varepsilon_{e}$, therefore, we used the dimensionless parameter which took account of gas densities:

$$
N^{*}=N\left(\rho_{\text {air }} / \rho\right)^{0.12}
$$

When the exponent of the ratio of the gas densities was 0.12 , the variation of the calculated and experimental $\varepsilon_{e}$ gave the minimum value. It is indicated from Fig. 7 that the voidage $\varepsilon_{e}$ could be correlated by $N^{*}$ :

$$
\varepsilon_{e}=\varepsilon_{m f}+4.03 / N^{*}
$$

The average value of $\varepsilon_{m f}$ for all powders used in this study was 0.477 . The value of $\varepsilon_{e}$ approached $\varepsilon_{m f}$ with increasing $N^{*}$. Therefore, for the system in which gas viscosity and density are low, $\varepsilon_{e}$ will be predicted better by Eq. (8) than by Eq. (5).

The relationship between $U_{m f}$ and $U_{s}$ shall be introduced by using Eq. (8). By adopting the relationship between $U_{m f}$ and $\varepsilon_{m f}$, and between $U_{s}$ and 


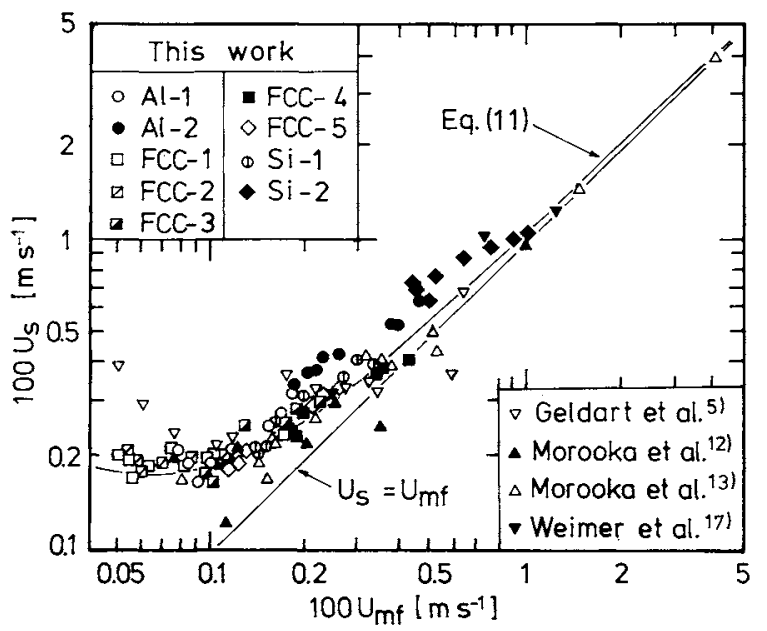

Fig. 4. Relationship between minimum fluidization velocity and sedimentation velocity.

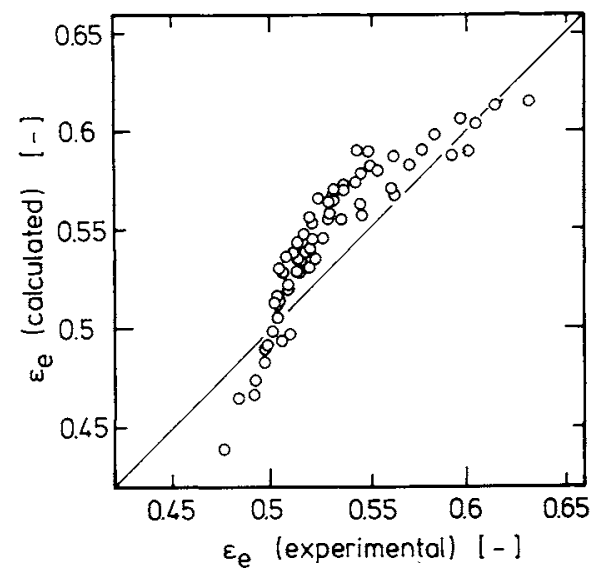

Fig. 5. Comparison of experimental values of $\varepsilon_{e}$ with those predicted by Abrahamsen and Geldart, ${ }^{2)}$ Eq. (5).

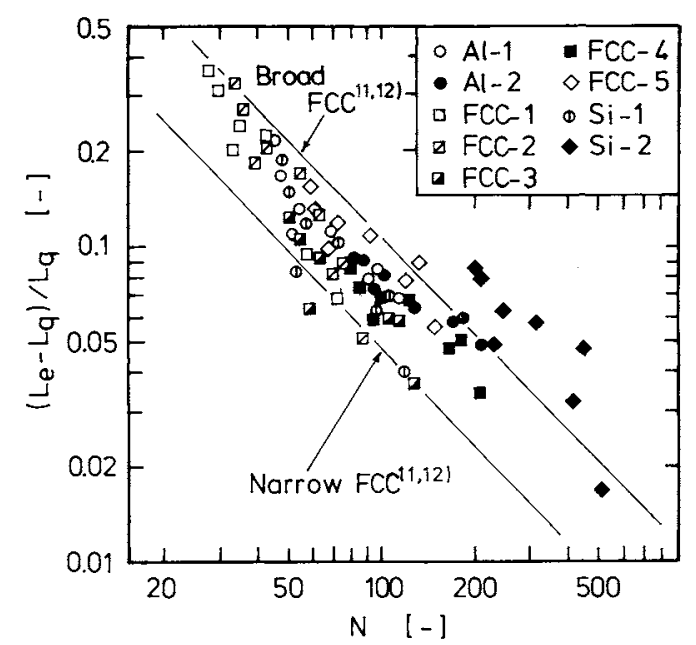

Fig. 6. Correlation of $\alpha$ with dimensionless number $N$, Eq. (6).

$\varepsilon_{e}$ in Eq. (3) we have

$$
U_{s}=U_{m f}\left(\frac{\varepsilon_{e}}{\varepsilon_{m f}}\right)^{5.8}
$$

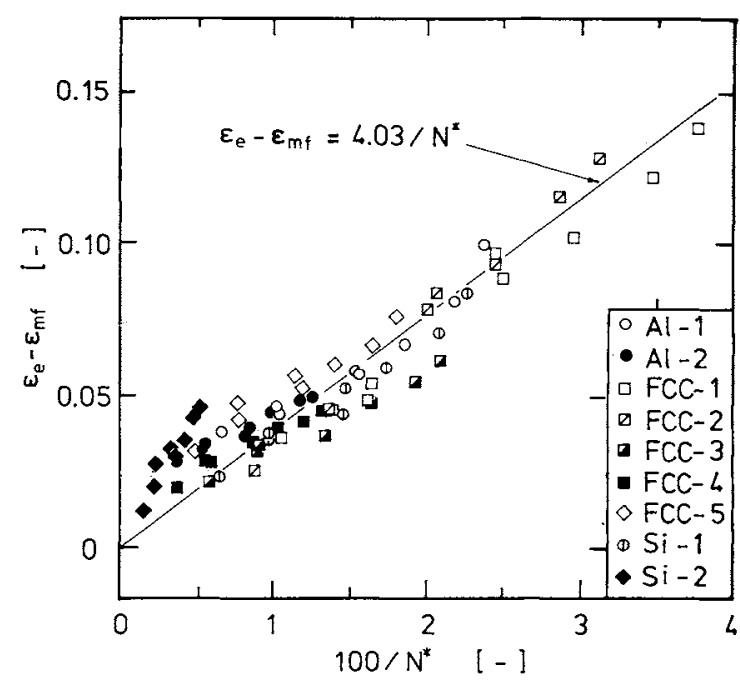

Fig. 7. Correlation of $\varepsilon_{e}-\varepsilon_{m f}$ with parameter $N^{*}$, Eq. (7).

We arrive at the following expression by replacing $\varepsilon_{e}$ with Eq. (8):

$$
U_{s}=U_{m f}\left[1+0.0064\left(\rho / \rho_{\text {air }}\right)^{0.12} \sqrt{g \bar{d}_{p}} U_{m f}^{-1}\right]^{5.8}
$$

The coefficient of $U_{m f}^{-1}$ in the second term in brackets varied between $0.88 \times 10^{-4}$ and $2.13 \times 10^{-4}$ for all gas-powder systems in this study. The velocity $U_{s}$ is influenced by the value of this coefficient in the region of small $U_{m f}$, whereas $U_{s}$ is not influenced in the region of large $U_{m f}$. Therefore, $\mathrm{Al}-2$ and $\mathrm{Si}-2$ powders were excluded for calculating the average value of the coefficient, which was found to be $1.2 \times 10^{-4}$.

Substitution of this value into Eq. (10) yields the following relationship between $U_{m f}$ and $U_{s}$ :

$$
U_{s}=U_{m f}\left[1+1.2 \times 10^{-4} U_{m f}^{-1}\right]^{5.8}
$$

Values calculated from Eq. (11) are shown in Fig. 4. The calculated $U_{s}$ increases with $U_{m f}$ when $U_{m f}$ is larger than $0.1 \mathrm{~cm} \mathrm{~s}^{-1}$ and is almost constant when $U_{m f}$ is smaller than $0.1 \mathrm{~cm} \mathrm{~s}^{-1}$. This is similar to the trend of the experimental data.

Equations (8) and (11) would be usable for Group $\mathrm{A}^{3)}$ powders and various gas systems under ambient conditions.

\section{Conclusions}

The characteristics of the emulsion phase in fluidized beds with fine particles were investigated for various gas-powder systems. The voidage in the emulsion phase $\varepsilon_{e}$ was correlated. with a parameter $N^{*}$ which took account of the effect of gas densities in the form of $\left(\rho_{\text {air }} / \rho\right){ }^{0.12}$ The voidage difference, $\varepsilon_{e}-\varepsilon_{m f}$, was found to be almost inversely proportional to $N^{*}$ (Eq. (8)). By using this relationship between $\varepsilon_{e}$ and $N^{*}$, the sedimentation velocity was approximated by a function of minimum fluidizing velocity. The proposed correlation, Eq. (11), can 
predict sedimentation velocity from minimum fluidizing velocity alone. Fairly good agreement was confirmed between the predictions and experimental data.

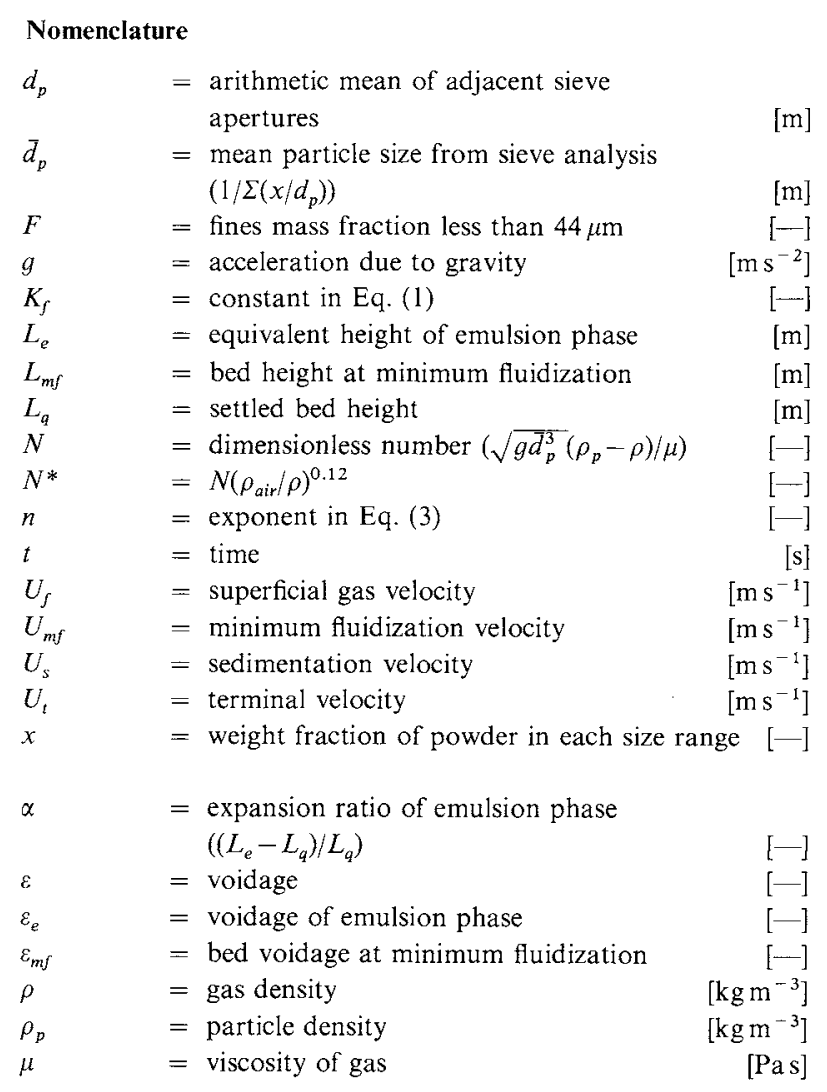

\section{Literature Cited}

1) Abrahamsen, A. R. and D. Geldart: Powder Technol., 26, 35 (1980).

2) Abrahamsen, A. R. and D. Geldart: Powder Technol., 26, 47 (1980).

3) Geldart, D.: Powder Technol., 7, 285 (1973).

4) Geldart, D. and A. C. Y. Wong: Chem. Eng. Sci., 39, 1481 (1984).

5) Geldart, D. and A. C. Y. Wong: Chem. Eng. Sci, 40, 653 (1985).

6) Guedes de Carvalho, J. R. F.: Chem. Eng. Sci., 36, 413 (1981).

7) Kai, T. and S. Furusaki: J. Chem. Eng. Japan, 18, 113 (1985).

8) Kai, T. and S. Furusaki: J. Chem. Eng. Japan, 19, 67 (1986).

9) Kunii, D. and O. Levenspiel: "Fluidization Engineering," Wiley, New York (1969).

10) Massimilla, L., G. Donsì and C. Zucchini: Chem. Eng. Sci., 27, 2005 (1972)

11) Miyauchi, T., S. Furusaki, S. Morooka and Y. Ikeda: "Advances in Chemical Engineering," Vol. 11, p. 275, Academic Press, New York (1981).

12) Morooka, S., M. Nishinaka and Y. Kato: Kagaku Kōgaku, 37, 485 (1973).

13) Morooka, S., K. Kusakabe, J. Igaki and Y. Kato: J. Chem. Eng. Japan, 18, 264 (1985).

14) Richardson, J. F. and W. N. Zaki: Trans. Instn. Chem. Engrs., 32, 35 (1954).

15) Rietema, K.: Proc. Int. Symp. on Fluidization, p. 154 (1967).

16) Simone, S. and P. Harriott: Powder Technol., 26, 161 (1980).

17) Weimer, A. W. and G. J. Quarderer: AIChE J., 31, 1019 (1985).

(A part of this paper was presented at the Hokuriku Meeting (Toyama, July 1986) of The Society of Chemical Engineers, Japan.) 